\title{
LA DESAPARICIÓN FORZADA DE 43 ESTUDIANTES DE AYOTZINAPA: ¿UN CASO DE AUTORÍA MEDIATA POR DOMINIO DE LA VOLUNTAD EN APARATOS ORGANIZADOS DE PODER?
}

(Apuntes para un debate)

Miguel ONTIVEROS ALONSO*

\section{Los hechos}

El 26 de septiembre de 2014, día de los hechos, tres estudiantes de la Escuela Normal Rural Raúl Isidro Burgos de Ayotzinapa, en el Estado Mexicano de Guerrero, fueron privados de la vida, veinticinco resultaron heridos y cuarenta y tres desaparecieron ${ }^{1}$. Las investigaciones de la Fiscalía General del Estado de Guerrero y de la Procuraduría General de la República han llevado a la detención de aproximadamente noventa y nueve personas, entre las que se encuentran el expresidente municipal de Iguala y su esposa, así como decenas de agentes de la Policía de los Municipios de Iguala y Cocula. También se encuentran procesados varios miembros del -así autodenominado- cartel de los «guerreros unidos» ${ }^{2}$. Para concluir con la ejemplificación de este caso y entrar a un breve análisis, quiero destacar los siguientes datos ${ }^{3}$ :

1. Algunos detenidos - hoy procesados- han manifestado que «procedieron» a realizar el operativo por una instrucción directa del entonces presidente municipal, quien habría ordena-

\footnotetext{
* Becario de la Fundación Alexander von Humboldt en el Instituto de Derecho Penal de la Universidad de Bonn, bajo la dirección académica del Prof. Dr. Dres. h.c. Urs Kindhäuser. Investigador (SNI) en el Instituto de Investigaciones Jurídicas de la Universidad Autónoma de Chiapas, México.

${ }^{1}$ La Procuraduría General de la República ha confirmado que las cenizas y huesos encontrados corresponden, por lo menos, a uno de los normalistas desaparecidos. Acerca de la estigmatización que sufren determinados grupos sociales -como sucede aquí con los alumnos y egresados de la Normal Isidro Burgos de Ayotzinapa- y el impacto que ello tiene en el sistema penal; Schroeder, Friedrich, Christian; Zweifel an der Asozialenkriminalisierung in der DDR; JZ; 1987; p 1004: Una característica, y atributo negativo del derecho penal de la DDR, ha sido la criminalización de los asociales. Lo mismo sucedió en la Unión Soviética con la campaña generada en contra de los -así denominados- «parásitos». La asocialidad (Asozialität) era vista -al igual que la criminalidad- como una expresión más del comportamiento social peligroso.

${ }^{2}$ El asunto que aquí se aborda se ha traducido, sin duda, en el desafío más importante para las instituciones mexicanas vinculadas a la procuración e impartición de justicia en las últimas décadas. Toda vez que la información y los avances en la investigación siguen fluyendo, me he limitado a relatar los hechos de una forma muy resumida. Para mayor información al respecto, puede verse el sitio oficial www.pgr.gob.mx del cual puede obtenerse información detallada y actualizada.

${ }^{3}$ La relatoría de los hechos, descrita aquí de forma muy breve, se fundamenta en información oficial -que es en mi parecer la más precisa- extraída de la «sala de prensa» de la Procuraduría General de la República, en la que se ubican los boletines con información detallada. La última información que he obtenido data del 2 de febrero de 2015 .
} 
do actuar contra los normalistas de Ayotzinapa que se encontraban en diversos autobuses en el Municipio de Iguala.

2. Según la Procuraduría General de la República se habría confirmado, también, que una vez detenidos los normalistas, los policías recibieron la instrucción de entregarlos a los miembros del cartel «guerreros unidos» - lo cual, según declaraciones de los propios detenidos, efectivamente sucedió-.

3. Los miembros del cartel, ahora detenidos, habrían asegurado dos cosas. Que su líder es la esposa del expresidente municipal y que los estudiantes habrían sido asesinados, sus cuerpos incinerados en un basurero municipal y sus cenizas lanzadas al río san juan.

4. El expresidente municipal de Iguala y su esposa se encuentran procesados por diversos delitos, entre otros, secuestro, delincuencia organizada y lavado de dinero, pero no por desaparición forzada de personas ${ }^{4}$.

Los hechos descritos se traducen en un desafío de enormes dimensiones para el Estado Mexicano y sus instituciones. Aquí abordaré sólo dos aspectos de la problemática: 1. Determinar si nos encontramos, o no, ante un delito de desaparición forzada de personas. 2. Determinar si nos encontramos, o no, ante un caso de autoría mediata, por dominio de la voluntad, en un aparato organizado de poder 5 .

\section{Los hechos sucedidos en Ayotzinapa frente al delito de desaparición forzada de personas}

Acreditar el delito de desaparición forzada de personas es uno de los mayores retos a los que se puede enfrentar un fiscal, no sólo por la complejidad de los elementos que lo configuran, sino también por las múltiples interpretaciones que se han desarrollado a escala internacional en esta materia. Si a ello se suma que en México existen varias modalidades de tipificación de este delito, destacando para los efectos de este caso la ley que en la materia se expidió en el Estado de Guerrero y el Código Penal Federal ${ }^{6}$, entonces la complejidad resulta aún mayor. No obstante, la doctrina - y de la mano de ésta los organismos internacionales de derechos humanos-, han generado una serie de líneas directrices que constituyen una guía estupenda para fiscales, abogados y jueces. De entrada, saltan a la vista varias divergencias existentes entre las dos legisla-

4 Algunas versiones que parecen sólidas, pero que no puedo confirmar porque no tengo acceso al expediente, señalan que, con buen sustento, la Procuraduría General de la República solicitó las órdenes de aprehensión -efectivamente- por el delito de desaparición forzada de personas. Sin embargo, el Juez de Distrito con sede en Matamoros, Tamaulipas, rechazó dicha solicitud con el argumento de que no quedaba suficientemente acreditado el elemento de «temporalidad» del delito de desaparición forzada, por lo que concedió las órdenes de aprehensión por los delitos de secuestro y delincuencia organizada. Acerca de una decisión como ésta, véase mi opinión al final del primer apartado de este artículo.

5 Además de la bibliografía -vinculada a esta temática- citada en el segundo apartado de este artículo; no puedo dejar de advertir aquí dos destacadas aportaciones de Christian Schroeder por lo que a este eje temático se refiere. En primer lugar, su obra «Der Täter hinter dem Täter, Ein Beitrag zur Lehre von der Mittelbaren Täterschaft», 1965. En segundo lugar, su artículo «Der Sprung des Täters hinter dem Täter aus der Theorie in die Praxis»; JR, 1995, p. 178. Mi parecer es que, para un primer acercamiento a su obra, este artículo (de apenas 4 páginas), resulta la vía ideal, pues expone una visión general de los fundamentos de su propia concepción -mediante una crítica a la postura de Roxin-, así como la relación entre este modelo de autoría y las resoluciones del BGH -a través de casos prácticos que resultan de fácil acceso para el estudiante-; (Katzenkönigs-Fall o el Mann-Vom-Sirius-Fall).

6 Resulta importante considerar ambas legislaciones, pues si bien es cierto el día 4 de octubre de 2014 la Procuraduría General de la República ejerció la facultad de atracción, los hechos sucedieron en el Estado de Guerrero, por lo que su Fiscalía continúa coadyuvando en las investigaciones. 
ciones que podrían aplicarse para el caso que nos ocupa ${ }^{7}$. Así, el Código Penal Federal establece lo siguiente:

Artículo 215-A. Comete el delito de desaparición forzada de personas, el servidor público que, independientemente de que haya participado en la detención legal o ilegal de una o varias personas, propicie o mantenga dolosamente su ocultamiento bajo cualquier forma de detención ${ }^{8}$.

Por otro lado, la Ley para Prevenir y Sancionar la Desaparición Forzada de Personas en el Estado de Guerrero ${ }^{9}$ contempla el tipo penal de la siguiente forma:

Artículo 3. Comete el delito de desaparición forzada de personas el servidor público que, en ejercicio de sus atribuciones o con motivo de ellas, detenga, prive de la libertad y mantenga oculta a una o más personas, o bien autorice, apoye o consienta que otros lo hagan, cualquiera que sea el método y motivación utilizados, sin reconocer la existencia de tal privación o niegue información fidedigna sobre el paradero de la o de las víctimas, impidiendo con ello el ejercicio de los recursos legales y las garantías procesales procedentes.

Serán igualmente considerados como sujetos activos del delito de desaparición forzada de personas aquellas que aun cuando no sean formalmente autoridades ni funcionarios, actúen aprovechando la autorización, el apoyo o la aquiescencia de funcionarios públicos ${ }^{10}$.

Por considerarlo de especial relevancia para los efectos del caso aquí analizado, me parece importante reproducir el artículo 10 de la ley guerrerense:

7 La multitud de tipos penales y normas sobre un mismo rubro -tal y como sucede en México-, en nada abona a la seguridad jurídica. Acerca de esta problemática y el «espacio de juego» concedido al legislador en materia penal; Schroeder, Friedrich-Christian; Die Bestimmtheit von Strafgesetzen am Beispiel des groben Unfugs; JZ; 1969; pp. 774-775. «En aquellos casos en que no haya claridad acerca del contenido de la ley, es aconsejable la interpretación conforme a la constitución. Sin embargo, aun así habrá problemas, pues la constitución suele hacer referencia sólo al punto nuclear del asunto a resolver», p. 778. En torno a la vinculación del legislador al principio de legalidad, véase también, Schroeder; La posesión como hecho punible; Traducción de Miguel Polaino-Orts; Revista de Derecho Penal y Criminología; $2^{a}$ Época, Número 14; pp. 167-168; «También la Constitución alemana determina que un "hecho" sólo puede ser penado cuando su punibilidad estaba legalmente prevista con anterioridad al momento en que el "hecho" fuere cometido (Art. 103 Abs. 2)».

8 Las consecuencias jurídicas del delito se contemplan a partir del artículo 215-B. «A quien cometa el delito de desaparición forzada de personas se le impondrá una pena de cinco a cuarenta años de prisión. Si la víctima fuere liberada espontáneamente dentro de los tres días siguientes a su detención, la pena será de ocho meses a cuatro años de prisión, sin perjuicio de aplicar la que corresponda a actos ejecutados u omitidos que constituyan por sí mismos delitos. Si la liberación ocurriera dentro de los diez días siguientes a su detención, la pena aplicable será de dos a ocho años de prisión, sin perjuicio de aplicar la que corresponda a actos ejecutados u omitidos que constituyan por sí mismo delitos». Artículo 215-C. «Al servidor público que haya sido condenado por el delito de desaparición forzada de personas, además se le destituirá del cargo y se le inhabilitará de uno a veinte años para desempeñar cualquier cargo, comisión o empleo públicos».

9 Más que una casualidad, es una causalidad que sea Guerrero donde se haya tipificado de forma más acabada el tipo penal de desaparición forzada, pues como lo destaca Grammer; «uno de los detonantes de este delito fue la situación de inestabilidad política que pudo haber variado en su intensidad: desde una auténtica guerra civil -como sucedió en El Salvador o Guatemala- pasando por un enfrentamiento armado con la guerrilla como sucedió en Perú, México o en la provincia argentina de Tucumán ...»; Grammer, Christoph; Der Tatbestand des Verschwindenlassens einer Person (Transposition einer völkerrectilichen Figur ins Strafrecht; Duncker und Humblot; Berlin; 2005; pp. 13-14.

${ }^{10}$ Las consecuencias jurídicas se contemplan en el artículo 4. A quien cometa el delito de desaparición forzada de persona, se le sancionará con pena privativa de la libertad de veinte a cuarenta años de prisión y multa de qui- 
Artículo 10. Se sancionará de tres a seis años de prisión y multa de doscientos a cuatrocientos salarios mínimos vigente en la región, a la autoridad superior jerárquica que orgánica y legalmente tenga el deber jurídico de actuar e impedir la desaparición forzada y que sin embargo no lo hiciere, permitiendo por ausencia en el orden de mando la perpetración del delito ${ }^{11}$.

\section{II.I Algunos aspectos relevantes del tipo objetivo}

\section{a) Un delito de dos actos}

Como puede apreciarse de ambas redacciones - y en armonía con Ambos/Böhm-, la desaparición forzada «requiere de dos actos: la privación de la libertad (que puede ser legal ab initio, a diferencia del secuestro), y la negativa a reconocer dicha privación o de dar noticia al respecto (elemento que no está presente en modo alguno en el secuestro ya que la obligación de informar sobre el secuestro implicaría una flagrante violación al derecho de no autoincriminarse») ${ }^{12}$. De lo anterior se desprende claramente que si falta cualquiera de las dos dimensiones señaladas no se integraría el tipo de desaparición forzada, por lo que la fiscalía tendría que ajustarse, en el mejor de los casos, a la aplicación de alguna de las modalidades típicas contempladas en la Ley General para Prevenir y Sancionar el Delito de Secuestro.

No obstante que las investigaciones ${ }^{13}$ siguen su curso y que cada día se generan avances por parte de la Procuraduría General de la República, todo parece indicar que las dos dimensiones (momentos) a las que se ha hecho mención aquí sí se verifican en el caso que nos ocupa. Así, presuntamente, después de recibir la orden de «proceder» por parte del presidente municipal, los agentes de la policía municipal de Iguala, en coordinación con policías municipales de Cocula, -además de disparar y matar a seis personas, tres de éstas estudiantes de Ayotzinapahabrían privado de la libertad a los 43 normalistas para horas más tarde entregarlos a miembros del cartel «guerreros unidos». A partir de ahí, los hoy imputados, es decir, el expresidente municipal y su esposa, al igual que los miembros de ambas policías, rechazan -expresamente

\footnotetext{
nientos a mil salarios mínimos vigentes en la región, destitución e inhabilitación para el desempeño de cualquier cargo, empleo o comisión hasta por el tiempo que dure la pena de prisión impuesta.

El que cometa este delito no tendrá derecho a gozar de la conmutación de sanciones, remisión parcial de la pena, tratamiento preliberacional, libertad preparatoria o cualquiera de los otros beneficios que la Ley respectiva establece.

${ }^{11}$ Según Grammer, las investigaciones realizadas dejan claro que en este delito siempre se da una participación del Estado. Ésta es obligatoria, aunque no necesariamente es una operación directa sino también a través de la figura del autor mediato; Der Tatbestand der Verschwindenlassens einer Person (Transposition einer völkerrechtlichen Figur ins Strafrecht; Max-Planck-Institut für ausländisches und internationales Strafrecht; Duncker und Hublot; 2005; p. 182.

${ }^{12}$ Ambos, Kai/Böhm, María Laura; «El tipo penal de la desaparición forzada de personas» (Análisis comparativo internacional y propuesta legislativa http://perso.unifr.ch/derechopenal/assets/files/articulos/a_20100617_03. pdfp. 8. También; Werle, Gerhard; Völkerstrafrecht; $3^{\text {a }}$ edición; Mohr Siebeck; 2012; p. 436-437.

${ }^{13}$ Las investigaciones en materia de desaparición forzada de personas siempre son complejas, como lo pone de relevancia Grammer; En ocasiones se finge que se investiga, así como se responde falsamente a las entrevistas. A esto se suma la circunstancia de que no se sabe nada de la víctima desaparecida; puede ser que no se tengan registros de su persona, se le haya retirado su documentación o que ya se encuentre en otro país ...; Quienes buscan a los desaparecidos suelen ser agredidos y amenazados. Muchos son víctimas de violencia o desaparición forzada y lo mismo puede suceder con sus familiares. Der Tatbestand; pp. 34-35.
} 
o mediante omisión-, la existencia de la privación de la libertad de las víctimas y niegan toda información respecto de su paradero.

Lo anterior se traduce, con otras palabras, en que los hoy imputados habrían propiciado dolosamente el ocultamiento de las víctimas, quienes siguen desaparecidas, mientras que algunos de los actores se dieron a la fuga, impidiendo de esta forma la obtención de información fidedigna sobre la suerte de los normalistas.

\section{b) El bien jurídico protegido}

Tal y como se desprende de la doctrina más avanzada, el primer reto que surge en esta materia, una vez que se ha comprendido que la verificación de los dos actos antes señalados son indispensables, es el relativo a la determinación del bien jurídico. Como lo han puesto de relevancia Ambos/Böhm, hay una multitud de opiniones al respecto. Así, por ejemplo, puede entenderse que «la desaparición forzada de personas protege «múltiples derechos esenciales», como la vida, la integridad física, la libertad, el derecho a no ser sometido a tortura y tratos o penas crueles, inhumanas o degradantes» ${ }^{14}$. Una de las opiniones que más llama la atención en este rubro es la de Galaín Palermo, para quien lo que verdaderamente se afecta en este rubro son «las capacidades, seguridades o circunstancias que son necesarias para el libre ejercicio de la vida social que asegura a su vez el libre ejercicio de los derechos humanos y la protección de éstos» ${ }^{15}$.

La legislación guerrerense coincide en la mención a la dignidad humana ${ }^{16}$, aunque sólo a escala de la exposición de motivos, dando a entender que considera a aquélla como el objeto de protección de la norma. Y pareciera que no falta razón a esta concepción, por lo que no veo obstáculo alguno para acreditar la lesión al bien jurídico en el caso de los normalistas desaparecidos en Guerrero, pues está claro que debido a los hechos de que fueron víctimas, se les impidió el ejercicio de recursos legales y cualquier tipo de garantía procesal. Así, parece bastante claro que privar de la libertad a un grupo de estudiantes, después de haber matado a otros más, transportarlos en camionetas oficiales, para más tarde entregarlos a un cartel de la delincuencia organizada - cuyos miembros, según las noticias oficiales, los habrían ejecutado con disparos en la cabeza e incinerado sus cuerpos en un basurero-, sí que afecta la dignidad humana de ellos y de sus familiares, quienes según los instrumentos internacionales y la legislación nacional también poseen la calidad de víctimas.

Si bien no observo problema para los efectos de acreditar en este caso la lesión al bien jurídico protegido, es decir, la dignidad de las víctimas, creo necesario - sobre todo de cara a la nueva Ley General que en esta materia se planteará en México- hacer un par de reflexiones al respecto. Mi parecer es que contemplar a la dignidad humana como objeto jurídico del delito de desaparición forzada de personas es un poco ambiguo: también las víctimas de violación sexual, de lesiones graves o de secuestro ven afectada su dignidad, pero el legislador ha decidido concretar el objeto de protección a escala legislativa, asumiendo a la libertad sexual, la integridad personal

\footnotetext{
${ }^{14}$ Ambos/Böhm; El tipo penal...; ob.cit. p.9 y ss. Sin embargo, reconoce finalmente tres niveles de afectación del bien jurídico: 1. Nivel individual: ámbito físico-psíquico de la víctima y su seguridad. 2. Nivel familiar: el derecho de los allegados a conocer de la situación, actuar jurídicamente en defensa de la víctima y conocer su destino. Y, 3. Nivel colectivo. Para Grammer; el bien jurídico es la «indemnidad de la persona» (Unversehrtheit der Person); Der Tatbestand...; ob.cit. p. 114, aunque es también de la opinión arriba citada que hace referencia a los tres niveles; p. 135. .

15 Ambos/Böhm; El tipo penal...ob.cit. p. 10.

${ }^{16}$ Por su lado -sin justificación- el Código Penal Federal contempla el delito de desaparición forzada de personas en el Título Décimo, intitulado, «Delitos cometidos por servidores públicos».
} 
y la libertad como bienes jurídicos respectivamente. Algo parecido sucede con la propuesta de Galaín Palermo, en torno a contemplar «los derechos humanos» como bien jurídico. Esto es ir demasiado lejos, pues el bien objeto de protección es en verdad difuso a la vez que poco claro. Sin embargo, por otro lado, contemplar a la libertad, la integridad física, el derecho a no ser sometido a tortura y tratos o penas crueles, inhumanas o degradantes, se queda corto. Esto no significa que no sean derechos esenciales o bienes de la mayor relevancia. Significa, más bien, que el delito de desaparición forzada de personas se traduce en una lesión mucho más grave que la sola libertad o integridad, o al derecho a no ser objeto de tortura o malos tratos.

Si se observa con atención, la víctima de desaparición forzada de personas es cosificada por su victimario, es decir, se le brinda un trato de objeto, de cosa, no de ser humano (de ahí que sea correcto considerar que se afecta su dignidad). Sin embargo, la afectación va más allá, pues durante el proceso de cosificación, es que se le impide ejercer cualquier otro derecho. Y no me refiero sólo al ejercicio de recursos legales o garantías procesales, sino exactamente a eso: a cualquier otro derecho, desde la dignidad y la libertad, hasta el ejercicio del derecho de propiedad. Con esto quiero decir que se anula su personalidad y que esto sucede en las tres dimensiones de la persona humana: la física (al ser maltratado, golpeado, lesionado, torturado), la espiritual (al ser extraído de su entorno social y de su familia), y la mental (al ser interrogado mediante violencia psicológica, amenazado y humillado).

Lo hasta ahora señalado muestra un gran parecido entre los delitos de desaparición forzada de personas y la trata de personas en sus diversas hipótesis de explotación: en ambos casos la víctima es una persona humana, a quien en su calidad de objeto de la acción se le cosifica, privándole de sus derechos más elementales, incluidas — en ambos delitos— su dignidad y libertad. En ambas modalidades delictivas se anula la personalidad de la víctima en sus tres dimensiones, ya que también las víctimas de trata y explotación son maltratadas, pues como sostiene Kindhäuser; «en esta variante nos encontramos ante una explotación sexual comercial de las víctimas de trata sexual, que son expuestas en el ámbito de la pornografía o en shows de tipo sexual $»^{17}$; extraídas de su entorno social y humilladas (en el caso de la trata de personas, son explotadas sexualmente, en trabajos o servicios forzados, en la servidumbre o - entre otras modalidades- se les extraen órganos, tejidos o componentes).

Por eso creo que el bien jurídico de la desaparición forzada de personas, así como en el delito de trata de personas, es el libre desarrollo de la personalidad, por lo que en caso de que las víctimas sean privadas de la vida, habría que sancionar en concurso de delitos con homicidio. El libre desarrollo de la personalidad se contempla, por lo menos, en las constituciones de Alemania, España y México y hay antecedentes en la literatura de los tres países que pueden sentar un basamento firme para su consideración en calidad de bien jurídico, tal y como se propone aquí1 $^{18}$. Así, por ejemplo, Kindhäuser:

\footnotetext{
${ }^{17}$ Strafrecht. Besonderer Teil I; Straftaten gegen Persönlichkeitsrechte, Staat und Gesellschaft; 6a edición; Nomos; 2014 , p. 169.

${ }^{18}$ No me puedo extender más aquí porque temo desviarme del tema principal (la desaparición de los cuarenta y tres normalistas de Ayotzinapa y la probable imputación a título de autoría mediata por dominio de la voluntad en un aparato organizado de poder). Sin embargo, ya he tratado este tema en otro lugar, donde se puede apreciar mi parecer; Ontiveros Alonso, Miguel; «Die freie Entfaltung der Persönlichkeit (Ein würdevolles Rechtsgut in einem Rechtsstaat)»; en; Strafrecht als Scientia Universalis; Festschrift für Claus Roxin; Manfred Heinrich, Christian Jáger, Hans Achenbach, Knut Amelung, Wilfried Bottke, Bernard Haffke, Bernd Schünemann y Jurgen Wolter; Tomo II, Walter de Gruyter; 2011, p. 245 y ss.
} 
«Las normas de conducta de carácter penal sirven —según la doctrina hoy absolutamente dominante- a la protección de bienes jurídicos. Bienes jurídicos son las cualidades de las personas, cosas o instituciones que - como el cuerpo, la vida, la libertad, la propiedad, la protección del derecho- sirven al libre desarrollo de cada quien en una sociedad democrática dentro de un Estado social y de derecho» ${ }^{19}$.

\section{c) La calidad del sujeto activo}

El Código Penal Federal, así como la Ley para Prevenir y Sancionar la Desaparición Forzada de Personas en el Estado de Guerrero exigen una calidad especial del sujeto activo. Así, la legislación federal señala que puede cometerlo «el servidor público, que independientemente de que haya participado en la detención legal o ilegal de una o varias personas...»; mientras que la legislación guerrerense, de corte más amplio y garantista, señala que «comete el delito de desaparición forzada de personas el servidor público que en ejercicio de sus atribuciones o con motivo de ellas...». Sin embargo, en el segundo párrafo del artículo 3 va más allá al señalar: «serán igualmente considerados como sujetos activos del delito de desaparición forzada de personas, aquellas personas que aun cuando no sean formalmente autoridades ni funcionarios, actúen aprovechando la autorización, el apoyo o la aquiescencia de funcionarios públicos».

El caso que nos ocupa no plantea desafíos importantes en este rubro, pues de las investigaciones realizadas por la Fiscalía guerrerense y la Procuraduría General de la República se desprende que el hoy imputado, en su calidad de presidente municipal -y por lo tanto de servidor público- habría emitido la orden verbal a la Policía bajo su mando de "proceder» en contra de los normalistas. Así mismo, quienes ejecutaron las detenciones —además de los seis homicidios del día 26 de septiembre eran agentes de las Policías Municipales de Iguala y Cocula, por lo que tenían también la calidad de servidores públicos.

Tampoco debiera plantear problema alguno la imputación por desaparición forzada de personas - por lo menos en torno a la calidad del sujeto activo- el asunto relativo a los miembros del cartel de «guerreros unidos». Éstos, a quienes les fueron entregados los normalistas por parte de los policías municipales y a quienes se les atribuye la privación de la vida e incineración de los estudiantes, actuaban en pleno acuerdo con la autoridad. Es decir, no sólo con su autorización, apoyo o aquiescencia, sino en clara coordinación. Esto se desprende no sólo de las declaraciones de policías y miembros del cartel, sino también de los testimonios que se han hecho públicos por parte de la Procuraduría General de la República, en el sentido de que la esposa del expresidente municipal, es la líder del grupo criminal.

\section{d) La negativa a admitir la privación de la libertad o a dar información sobre la suerte o el paradero de las personas}

Como se señaló al principio, el delito de desaparición forzada es un delito «de dos actos». El primero, al que se ha hecho referencia hasta ahora, es el relativo a la privación de la libertad, mientras que el segundo consiste en negar dicha privación de la libertad o bien no dar información acerca de la víctima. De aquí se desprende que la segunda dimensión típica se refleja en

\footnotetext{
${ }^{19}$ Strafrecht. Allgemeiner Teil; 6a edición, Nomos, Baden-Baden; 2013; p. 36. Acerca de los desafíos que representa la protección los derechos fundamentales para el proceso penal, en especial frente a la dignidad humana y el libre desarrollo de la personalidad, Schroeder, Friedrich-Christian; Grenzen der Rationalisierung des Strafverfahrens; NJW; 1983; p. 139.
} 
una omisión por parte del sujeto activo, quien puede ubicarse en cualquiera de las dos hipótesis. Y que esto sea así, me parece, se encuentra perfectamente justificado, pues negar la propia privación de la libertad o no dar información al respecto - al igual que dar información, pero que ésta sea falsa - tienen exactamente el mismo resultado: dejar a la víctima fuera del amparo de la ley.

Aquí vale la pena destacar la sentencia de la Corte Constitucional de Colombia, citada por Ambos/Böhm; en la que se establece que «no es necesario el requerimiento para dar información o la negativa a reconocer la privación de la libertad, sino que basta la falta de información sobre el paradero de la persona ${ }^{20}$. Así, para el caso que nos ocupa, resulta que el probable «autor de escritorio» - expresidente municipal- y su esposa, omitieron brindar cualquier información acerca del paradero de los normalistas, pues días después de sucedidos los hechos se dieron a la fuga. Más aún, después de ser detenidos, se negaron a declarar al respecto. Algo parecido sucedió con los policías municipales que privaron de la libertad a los normalistas, pues mientras algunos huyeron, otros sí dieron información, pero falsa, que además de distraer las investigaciones efectuadas por la Procuraduría General de la República, mantienen a las víctimas fuera del amparo de la ley.

En el marco de sus declaraciones primarias algunos policías señalaron que los normalistas habían sido ejecutados y sus cuerpos enterrados en fosas. Si bien es cierto que estas declaraciones distrajeron las primeras investigaciones, llevaron también a encontrar múltiples fosas clandestinas con decenas de cuerpos (ninguno de éstos pertenecía a alguno de los 43 normalistas).

Finalmente, vale la pena destacar la opinión de Werle, para quien no basta omitir la información respecto del destino de las personas privadas de la libertad para colmar el tipo. Resulta necesario, según el autor, requerir la información respecto del paradero de la víctima seguida de una negativa a dar dicha información ${ }^{21}$.

\section{II.II. Acerca del tipo subjetivo}

A partir de la desaparición de los normalistas de Ayotzinapa se ha desatado una serie de especulaciones acerca de si la imputación que en su caso se verifique, debiera ser por alguna modalidad de secuestro o, en su caso, por desaparición forzada de personas. Ya se han señalado aquí algunas breves reflexiones acerca de los contornos del tipo objetivo. Resta, sin embargo, advertir que el tipo subjetivo resulta determinante para poder calificar el hecho en su calidad de desaparición forzada de personas. Debido a la deficiente tipificación del artículo 215-A del Código Penal Federal, podría resultar complejo distinguir claramente los supuestos. Sin embargo, las dudas pueden disolverse si se observa, por ejemplo, el artículo 7 del Estatuto de Roma de la Corte Penal Internacional que establece:

i) Por «desaparición forzada de personas» se entenderá la aprehensión, la detención o el secuestro de personas por un Estado o por una organización política, o con su autorización, apoyo o aquiescencia,

\footnotetext{
${ }^{20}$ El tipo penal; ob.cit. p. 16.

${ }^{21}$ Esta negativa también abarca el tipo subjetivo; Werle, Gerhard; Völkerstrafrecht; $3^{\text {a }}$ edición; Mohr Siebeck; Tübingen; pp. 437-438.
} 
seguido de la negativa a admitir la privación de libertad o dar información sobre la suerte o el paradero de esas personas, con la intención de dejarlas fuera del amparo de la ley por un periodo prolongado

Esta redacción es recogida parcialmente por la legislación guerrerense, que siendo más sólida que la federal, establece al final lo siguiente: «...impidiendo con ello el ejercicio de los recursos legales y las garantías procesales procedentes». También el Código Penal Internacional Alemán, en su apartado 7.7 contiene este requisito:

\section{$\$ 7$ Crímenes contra la Humanidad}

(1) El que en el marco de un ataque generalizado o sistemático contra una población civil

7. Mantenga desaparecida por la fuerza a una persona con la intención de sustraerla durante largo tiempo a la protección de la ley.

a. Secuestrándola o privándola gravemente de su libertad física de cualquier otro modo por orden o con la tolerancia de un Estado o de una organización política, sin que en lo sucesivo se atienda sin demora la demanda de información sobre su suerte o paradero.

b. Negándose, por orden de un Estado o de una organización política o en contra de una obligación legal, a proporcionar sin demora información sobre la suerte o paradero de una persona que ha sido privada de su libertad física bajo las condiciones de la letra a, o proporcionando una información falsa.

Lo antes reproducido deja claro que, además de ser un tipo eminentemente doloso, debe concurrir en el autor un elemento subjetivo del injusto distinto al dolo cuyo contenido es precisamente lo que se acaba de reproducir más arriba. Y si ese elemento subjetivo no se verifica, no podríamos afirmar que nos encontramos ante un tipo de desaparición forzada. De ahí que, cuando en los medios de comunicación se señala que «el miembro de las fuerzas armadas que priva de la libertad a su mujer para después matarla y enterrar su cuerpo» cometería también el delito de desaparición forzada, se olvida que debe concurrir un ánimo específico en el autor, lo que no sucede en el ejemplo del miembro de las fuerzas armadas.

Por eso es que el dolo debe incluir, además de la privación de la libertad, la intención de dejar a la víctima "fuera del amparo de la ley por un periodo prolongado» (según el ECPI) o bien, de conformidad con la ley del Estado de Guerrero, impedir el ejercicio de los recursos legales y las garantías procesales procedentes. Así, como destacan Ambos/Böhm; «la desaparición forzada sólo puede ser cometida en forma dolosa. Y debe cometerse además, con la intención de dejar fuera del amparo de la ley a la persona que es privada de su libertad. Este requisito subjetivo del tipo hace del dolo un dolo más intenso con respecto al elemento volitivo" ${ }^{22}$. Con base en ello, proponen la siguiente redacción típica ${ }^{23}$ :

«Desaparición forzada de personas».

1. El Estado o particular que actúe con la autorización, apoyo o aquiesencia del

${ }^{22}$ El tipo penal...; ob.cit. p. 55. El mismo autor, en su propuesta de «tipo penal» incluye, también, este elemento subjetivo del injusto: «... con la intención de dejar a esa persona fuera del amparo de la ley, será penado con...»; ob.cit. p. 57.

${ }^{23}$ El tipo penal; ob.cit. p. 57. 
Estado, que en el marco de un ataque sistemático o generalizado a una población civil:

(1) privare a una persona de su libertad por cualquier medio, y luego no informare sobre la privación de la libertad o sobre el paradero o suerte de esa persona dentro del plazo legalmente estipulado o, en su defecto, en el plazo de cuarenta y ocho horas, o denegare dicha información al ser ésta debidamente requerida; o

(2) no informare sobre la privación de la libertad o sobre el paradero o suerte de la persona privada de su libertad dentro del plazo legalmente estipulado o, en su defecto, en el plazo de cuarenta y ocho horas a partir de haber tomado conocimiento sobre la privación de la libertad a que hace referencia el apartado anterior, o denegare dicha información al ser ésta debidamente requerida, con la intención de dejar a esa persona fuera del amparo de la ley, será penado con ...

$\mathrm{Al}$ respecto, aunque muy difícil de compartir, la concepción de Werle/Burchards es que «el dolo debe abarcar no sólo la privación de la libertad, sino también el privar por un periodo prolongado a la víctima de la protección de la ley» ${ }^{24}$. Como expondré de inmediato, sin duda resulta correcto sostener que el dolo debe abarcar, también, la privación a la víctima de la protección de la ley. Parece, sin embargo, arbitrario exigir que esa privación tenga una duración mínima de determinadas horas.

\section{Toma de postura}

Las breves reflexiones expuestas hasta ahora permiten afirmar que el caso de los cuarenta y tres normalistas de Ayotzinapa cumple con los elementos mínimos para configurar el delito de desaparición forzada de personas. Así, en su calidad de Presidente Municipal de Iguala, es decir, de servidor público, el hoy imputado habría ordenado a la Policía a su cargo proceder en contra de los normalistas. Después de realizar disparos en contra de los estudiantes, debido a lo cual fallecieron tres de éstos, veinticinco quedaron heridos y cuarenta y tres fueron privados de su libertad, los agentes de la Policía habrían entregado a los normalistas a miembros del cartel «guerreros unidos». Mediante la privación de la libertad y la entrega de los estudiantes a los miembros del crimen organizado, se impidió a los hoy desaparecidos protegerse mediante el amparo de la ley, mientras que al mismo tiempo, se violaron sus derechos humanos más fundamentales. Con la finalidad de evadir su responsabilidad, los agentes de las Policías de Cocula e Iguala y los miembros del cartel de guerreros unidos habrían hecho todo lo posible para evitar dejar rastro de los estudiantes, alterando drásticamente las distintas escenas del crimen y negando cualquier información en torno a los hechos, incluido el destino de los normalistas.

En torno al tipo subjetivo, me parece bastante claro que el dolo de los agentes de la policía abarcaría el elemento subjetivo consistente en dejarles fuera del amparo de la ley. Y esto es así pues, al contrario de como debió suceder en armonía con el ordenamiento jurídico, -es decir, poner a los detenidos a disposición de la Fiscalía estatal para los efectos de continuar la investigación bajo el amparo de las garantías procesales-, habrían sido entregados al crimen organizado con todo lo que ello significa. Afirmar lo contrario, es decir, que no se acredita el elemento

\footnotetext{
${ }^{24}$ En, Münchener Kommentar; \$7; Nebenstrafrecht III; Volkerstrafgesetzbuch; Beck; Múnich; 2009 , p. 608.
} 
subjetivo del injusto distinto al dolo consistente en privarlos del amparo de la ley, resultaría francamente insostenible.

Resta, sin embargo, atender un último punto que me parece fundamental. Recientemente se ha dado a conocer una resolución del Juzgado Federal que recibió las solicitudes de órdenes de aprehensión por parte de la Procuraduría General de la República. El Juzgado Federal, con sede en Matamoros, Tamaulipas, habría negado las órdenes de aprehensión por el delito de desaparición forzada de personas y las habría concedido por el delito de secuestro con resultado de muerte. El argumento habría sido que no se configura el delito de desaparición forzada de personas debido a que la temporalidad, es decir, el tiempo transcurrido entre la privación de la libertad y la vida, no fue lo suficientemente amplio. Este es un argumento que no se puede compartir, pues además de carecer de un fundamento técnicamente sólido, adolece de una perspectiva de derechos humanos, con especial referencia a las víctimas. Así, como sostiene Galaín Palermo:

«La desaparición se consuma precisamente cuando el autor "hace desaparecer" a la persona privada de la libertad al omitir brindar información, y sustraer de este modo a la víctima de sus derechos y de la capacidad de defensa (nivel personal de afectación del bien jurídico) e impedir que la administración de justicia pueda ejercer sus funciones y deberes jurisdiccionales y de protección (nivel colectivo de afectación del bien jurídico)» ${ }^{25}$.

El tipo penal de desaparición forzada de personas no exige un determinado grado de temporalidad para los efectos de su consumación. Y esta observación vale para ambas legislaciones mexicanas; la Federal y la del Estado de Guerrero, por lo que no veo cómo justificar una determinación como la señalada en armonía con nuestro ordenamiento jurídico. Sin embargo, es cierto que existe un debate acerca de si una privación de la libertad de muy corto plazo puede configurar el delito. Para tales efectos, la opinión de Ambos/Böhm resulta relevante:

«El ECPI tiene en su texto una expresión que podría llevar a confusión, cuando describe el elemento intencional del delito: "con la intención de dejarlas fuera del amparo de la ley por un período prolongado (...) La idea de ese período debe ser considerada por tanto tan corta como sea posible, sin poder ser más extensa que el período mínimo reconocida por la normativa internacional» ${ }^{26}$.

Efectivamente, tanto el Estatuto de Roma de la Corte Penal Internacional, como el Código Penal Internacional Alemán citados aquí tan sólo a manera de orientación-, exigen una determinada duración en la privación de la libertad para que ésta sea constitutiva del delito de desaparición forzada de personas. Este requisito, sin embargo, no se contempla en nuestra legislación, por lo que incorporarlo en una resolución judicial sería, me parece, ilegítimo. Ahora bien, suponiendo sin conceder que la fundamentación de dicho requisito se pudiese lograr al amparo de instrumentos internacionales, valdría la pena señalar que el delito de desaparición forzada queda consumado con la ejecución del segundo acto, sin importar que la privación de la libertad haya durado veinticuatro horas o menos.

Con lo arriba señalado quiero decir que, cuando policías y miembros del crimen organizado, presuntamente liderados por el expresidente municipal, privan de la libertad a los normalistas

${ }^{25}$ Citado por Ambos/Böhm; El tipo penal...; ob.cit.p 14.

${ }^{26}$ Ambos/Böhm; El tipo penal...; ob.cit. p. 41. 
con la finalidad de sustraerlos de la protección de la justicia, y niegan cualquier información respecto de su paradero, es en ese momento cuando ha quedado consumado el delito, sin importar el tiempo que han durado privados de la libertad.

Para comprender mejor lo hasta ahora señalado basta con hacer referencia al bien jurídico. Si asumimos aquí que el objeto de protección es la dignidad o el libre desarrollo de la personalidad, o incluso, - como sostiene Galaín- el libre ejercicio de los derechos humanos, parece del todo claro que ese objeto de protección queda gravemente lesionado cuando, con la finalidad de privarles de la protección del orden jurídico, las víctimas son privadas de la libertad y se niega tal hecho, así como cualquier información sobre su paradero, por parte de los autores. De hecho, como resulta evidente, esta situación se mantiene así desde hace un año.

\section{III. ¿Es la desaparición de los cuarenta y tres estudiantes de Ayotzinapa un caso de autoría mediata por dominio de la voluntad en aparatos organizados de poder?}

Ampliamente difundida en el ámbito de la justicia penal, la teoría de la autoría mediata por dominio de la voluntad en aparatos organizados de poder, formulada por Claus Roxin en $1963^{27}$, revolucionó la forma de resolver crímenes - de corte francamente similar al abordado aquí-, a escala internacional. Casos como el de los homicidios imputados a Eichmann ${ }^{28}$ o Staschynskij en Alemania, las desapariciones, secuestros y homicidios imputados a Alberto Fujimori Fujimori $^{29}$, expresidente en el Perú ${ }^{30}$, o los sesenta y nueve homicidios imputados al líder de Sende-

${ }^{27}$ En su obra; Täterschaft und Tatherrschaft, 1a edición, 1963, Walter de Gruyter; pp. 242 y ss. Del mismo año, su artículo tan breve como contundente, «Straftaten im Rahmen organisatorischer Machtapparate», Goltdammers Archiv für Strafrecht; 1963, pp. 193 y ss.

${ }^{28}$ Véanse las consideraciones de Roxin al respecto; Straftaten...; ob.cit. p. 193-201. De forma muy resumida, se trata del juicio seguido a los integrantes del Consejo de Defensa Nacional por los disparos efectuados a quienes intentaban saltar el muro que dividía las dos alemanias.

${ }^{29}$ Una de las imputaciones al Ex Presidente tiene tal similitud con los hechos de Ayotzinapa, que por lo menos, debiera llamar la atención; al respecto, véanse los datos señalados por Caro Coria, Dino Carlos; Sobre la punición del ex presidente Alberto Fujimori Fujimori como autor mediato de una organización criminal estatal; ZIS11/2009; «El mismo destacamento colina fue el autor directo de otro de los casos materia del proceso, llamado caso «La Cantuta». Así, el 18.7.1992, este grupo ingresó a la Universidad "Enrique Guzmán y Valle” -conocida como «la Cantuta»-, a bordo de dos camionetas pick up, organizados en varios sub grupos, todo ellos encapuchados y portando armas de fuego con silenciadores. Se dirigieron a la residencia de los estudiantes, los sacaron de sus dormitorios y los llamaron en base a una lista, separando del grupo a 9 estudiantes. Luego de la operación, procedieron a llevarse a los intervenidos en las camionetas antes indicadas, y cuando se encontraban por el Km. 1.5 de la autopista Ramiro Prialé, detuvieron los autos y bajaron a los detenidos. Fue en ese lugar donde los mataron y enterraron; p. 581.

${ }^{30}$ Al respecto; Pariona Arana, Raúl; La autoría mediata por organización en la Sentencia contra Fujimori; www. zis-online.com (11/2009); «El 7.4.2009 la Corte Suprema del Perú condenó al ex presidente Alberto Fujimori Fujimori como autor mediato de crímenes contra la humanidad por el asesinato y posterior desaparición de un profesor y nueva estudiantes de la Universidad Enrique Guzmán y Valle (La Cantuta), por la muerte de diecisiete personas en una quinta del distrito limeño de Barrios Altos y por el secuestro de un empresario y un periodista. Para fundamentar el tipo de participación criminal que desplegó el ex mandatario peruano, la sentencia se basó en la teoría de la autoría mediata por organización»; p. 609. Crítico, al respecto, Jakobs, Günther; quien sostiene la tesis de imputación por coautoría; Zur Täterschaft des Angeklagten Alberto Fujimori Fujimori; ZIS 11/2009; p. 572. También; Velásquez Velásquez; Fernando; «la teoría de la autoría mediata no se puede sostener porque es sofista y ambigua: da por hecho que existe una única forma de construcción de los aparatos organizados de poder criminales, lo cual no es correcto. Asume que todos los aparatos funcionan de la misma manera a pesar de que está claro que son diferentes y que cada uno tiene sus propias características»; Paramilitärische Führer und kriminelle Machtapparate; en; Streitbare Strafrechtswissenschaft; Festschrift für Bernd Schünemann zum 70 Geburtstag; Roland Hefendehl, Tatjana Hörnle und Luis Greco; De Gruyter, Berlin 2014; p. 1130. Crítico, aunque 
ro Luminoso ${ }^{31}$ en el mismo país, son una muestra de la capacidad de rendimiento que la teoría roxiniana tiene en la procuración e impartición de justicia. La eficacia de la teoría puede observarse, asimismo, en las resoluciones que, asumiendo esta concepción, ha dictado hace apenas unos años la Corte Penal Internacional en el caso Katanga ${ }^{32}$, condenado por crímenes de guerra y lesa humanidad ${ }^{33}$.

Roxin señala, como uno de los ejes rectores de su concepción, que «la decisión acerca de si se es autor o partícipe, no puede depender de las valoraciones de cada juzgador en lo individual, sino que dependerá exclusivamente de los presupuestos objetivos de la ley» ${ }^{34}$. En la teoría del dominio del hecho, por dominio de la voluntad en aparatos organizados de poder, se abordarían -según Roxin- los casos de autoría mediata en los que el líder - quien domina la organización - controla todo el proceso delictivo, es decir, donde «la organización funciona automáticamente sin que sea necesario que el líder se haga presente» ${ }^{35}$. Así, serían cuatro los pilares básicos sobre los que se construye la teoría brevemente comentada: 1. El poder de mando, 2. El apartamiento del derecho, 3. la fungibilidad de los ejecutores, y 4. La predisposición a la realización del hecho ilícito ${ }^{36}$. ¿En qué consisten estos elementos básicos $-\mathrm{y}$ en caso de ser factible - cómo aplicarían al caso de los normalistas de Ayotzinapa? El sistema penal mexicano asume una concepción diferenciadora de la intervención delictiva que distingue entre autores y partícipes. Así, la autoría mediata constituye una forma de autoría principal que se verifica cuando el delito es realizado por el «hombre de atrás» o «autor de escritorio», a través de otra persona quien lo realiza materialmente.

Mi parecer es que, ya con base en la teoría de Roxin, habría que descartar las posibilidades de imputar la comisión de los delitos que aquí se verifican -me centro en la desaparición forzada de personas-, con base en el dominio del error del ejecutor o el dominio por coacción de la voluntad, de tal forma que podamos centrar la atención en la hipótesis del dominio de la voluntad. Y esto es así, porque, tal y como se desprende de las investigaciones realizadas por la

al mismo tiempo aceptando la relevancia de la propuesta roxiniana; Caro John, José Antonio; Manual teóricopráctico de teoría del delito; Instituto Max Planck para el Derecho Penal Extranjero e Internacional; $2014 ;$ p. 206.

31 Abimael Guzmán; líder de esa organización criminal.

${ }^{32}$ Al respecto, Ambos, Kai; Sobre la «organización en el dominio de la organización»; InDret 3/2011; p. 12; «En el proceso de la CPI contra los líderes milicianos Katanga y Ngudjolo Chui, se aborda la imputación de crímenes contra la humanidad y crímenes de guerra que fueron cometidos en febrero de 2003, en un ataque conjunto de ambos grupos milicianos por miembros de las asociaciones lideradas por dichos procesados, en donde la estructura de mando de ambos grupos estaba estrictamente dividida (por la pertenencia étnica disímil de sus miembros). No obstante, la Sala de Asuntos Preliminares de la CPI imputó a los procesados -mediante una curiosa combinación de autoría mediata (dominio de la organización) y coautoría como coautoría mediata ("mittelbare Mittäterschaft) (indirect co-perpetration)- no sólo los hechos de los propios subalternos, sino también los de cada uno de los otros, ya que habían intervenido en virtud de un plan común, siempre habían efectuado una contribución fundamental y habían controlado conjuntamente la totalidad del asalto».

${ }^{33}$ Crítico en torno a la teoría del dominio del hecho -con argumentos sólidos-; Kindhäuser, Urs; «De esto resulta lo siguiente: si el dominio del hecho se identifica con la capacidad de acción necesaria para evitar la realización del tipo, entonces es claro que el dominio del hecho sólo puede estar referido al propio comportamiento contrario a deber, y nunca a un comportamiento contrario a deber de alguna otra persona (...) En ningún caso puedo dominar, a través de mi contribución, una infracción del deber ajena. (...) En la medida en que la teoría del dominio sostiene algo distinto, ella finge hechos y atenta así contra el principio de culpabilidad»; en, Infracción de Deber y Autoría - Una Crítica a la Teoría del Dominio del Hecho; Traducción de Juan Pablo Mañalich R; Revista de Estudios de la Justicia; No 14 - año 2011; pp. 46-47.

34 Straftaten ...; ob.cit.; p. 197.

35 Straftaten...; ob.cit; p. 200.

${ }^{36}$ Roxin aplica estos cuatro criterios -expuestos ya desde su obra de 1963- en sus comentarios a la sentencia de Fujimori; Bemerkungen zum Fujimori-Urteil des Obersten Gerichtshof in Peru; ZIS 11/2009; p. 565. 
Procuraduría General de la República, los autores materiales de la desaparición de los normalistas -aunque no los únicos que participaron en los hechos-, serían policías. Es decir, servidores públicos, al mando de un Presidente Municipal, quien se encontraba en la cúspide del entramado institucional, y por tanto, todos ellos son miembros del Estado. Véase, al respecto, el artículo 29 de la Ley Orgánica del Municipio Libre del Estado de Guerrero:

Los ayuntamientos, a propuesta de los Presidentes Municipales, nombrarán a los siguientes servidores públicos, sin perjuicio de la denominación o rango jerárquico que los propios Ayuntamientos establezcan:

Jefe de Seguridad Pública, quien deberá reunir los requisitos previstos en la Ley de Seguridad Pública del Estado de Guerrero, además de ser previamente evaluado, capacitado y certificado por las estancias (sic) estatales competentes.

Que los autores materiales sean miembros del Estado no excluye la posibilidad, por ese sólo hecho, de que aplique alguna de las otras formas de autoría mediata - por error o por coaccióna las que se ha hecho referencia. Sin embargo, ningún dato hay que conduzca a la hipótesis, en el sentido de que al disparar y privar de la libertad a los normalistas, los agentes municipales de Iguala y Cocula se hubieran encontrado "coaccionados» o bajo un «error» en torno al operativo que implementaban. Por el contrario, las investigaciones de la Procuraduría General de la República, que ha hecho públicos testimonios de los imputados y hoy procesados, permiten apreciar que los policías actuaban con claro conocimiento de lo que hacían: sabían que los normalistas eran estudiantes, que se transportaban en un determinado número de autobuses y que habrían seguido instrucciones del mando superior, es decir, el hoy procesado y expresidente municipal de Iguala y su esposa. Esto elimina cualquier hipótesis de error o coacción, por lo que en mi parecer, es posible aplicar la figura de la autoría mediata, por dominio de la voluntad, de conformidad con los cuatro requisitos arriba señalados. Todo ello, en el entendido de que al momento de suceder los hechos existía previamente una organización estatal estructurada: el «Municipio Libre de Iguala de la Independencia», su policía y la policía municipal de Cocula ${ }^{37}$.

\section{Presupuestos específicos:}

\section{El poder de mando}

El poder de mando es un pilar básico de la autoría mediata. Éste se manifiesta en la capacidad para dictar órdenes y para que éstas se cumplan. Con palabras de Roxin; «basta que el líder de la organización presione un botón, para que el resultado se produzca, sin necesidad de que el líder conozca al autor material. Sin que sea necesario que acuda al error o a la amenaza ${ }^{38}{ }_{»}$. Aunque introduce algunos conceptos no sostenidos por Roxin, la sentencia dictada por la Sala Penal Especial de la Corte Suprema de Justicia de la República del Perú, en el caso Fujimori, resulta ejemplificadora al elaborar su argumentación respecto de este primer elemento:

«... la denominada autoría mediata se presenta cuando el hombre de atrás se aprovecha de los sujetos que se encuentran subordinados a otros en un aparato organizado de poder de tal suerte que por esa vía el primero mantiene un dominio objetivo del hecho -autoría mediata

\footnotetext{
37 Ambos municipios, colindantes, del Estado Mexicano de Guerrero.

${ }^{38}$ Straftaten; ob.cit.; p. 200. 
por dominio de la organización-; que ésta última se sustenta en dos elementos esenciales: existencia de un aparato de poder estructurado y la predisposición de los ejecutores; que el acusado tuvo una intervención vertical en los delitos imputados - ejecutados materialmente por efectivos de inteligencia militar en torno al Grupo Colina y al SIE-, en los que se dio una división de funciones y una línea jerárquica en la organización, en cuya cúspide se encontraba». ${ }^{39}$

En casos como en el del Perú con el Presidente de la República o en Iguala con el presidente municipal, nos encontramos directamente con un sujeto -el líder de la organización-, que se ubica en la punta de la pirámide, reconocido por la literatura como autor de escritorio: éste imparte órdenes y el resto del aparato las cumple sin cuestionarlas. Este se verifica, toda vez que el presidente municipal - hoy procesado- habría tenido, debido a su investidura, la capacidad para impartir órdenes directas en su calidad de líder de la organización (Municipio), así como también podría estar seguro de su cumplimiento, debido a la estructura funcional del aparato (todos los agentes de la policía municipal de Iguala se encontraban subordinados a él, debido a su calidad legítima de presidente municipal).

Que el hoy procesado habría poseído el dominio de la organización, y por tanto tiene la calidad de autor mediato por dominio de la voluntad, lo deja claro no sólo la constitución funcional del Municipio -en el que constitucionalmente ejercía todo el mando-, sino también los vínculos delictivos con el crimen organizado que las propias investigaciones habrían arrojado. Esto es, que él y su esposa - también detenida y procesada-tendrían fuertes vínculos con el cartel de guerreros unidos - cartel al que los policías entregaron a los normalistas- del que la esposa del expresidente municipal sería líder. En este sentido, véase la argumentación de la Corte Suprema del Perú, citando a Roxin:

En consecuencia, el hombre de atrás podrá confiar siempre en que su orden o designio criminal se van a cumplir sin necesidad de que tenga que conocer al ejecutor inmediato. (...) Por tanto, no será indispensable que exista una disposición expresa y que esté contenida en un documento, por la que el nivel superior estratégico ordene directamente el cumplimiento de una función específica al ejecutor inmediato ${ }^{40}$.

Que en este modelo de autoría mediata el «autor de escritorio» no conozca a los autores materiales del delito en nada afecta a la imputación de responsabilidad. Incluso, tal y como lo advierte el propio Roxin al abordar el proceso instaurado a Eichman; «la cercanía o lejanía del autor mediato con el autor material - que mata directamente a la persona- no tiene absolutamente ninguna relevancia de cara a la responsabilidad del primero ${ }^{41}$. La Corte Suprema del Perú va más allá y señala:

«Cabe destacar, en este contexto, que el grado de reprochabilidad que ha de recaer sobre el titular del poder de mando será siempre más intenso cuando el origen del mismo parte de un marco de legitimidad formal» ${ }^{42}$. En estos casos, pues, corresponderá un mayor grado de desvalor, porque aquél, abusando de su posición de dominio produce una doble afectación al sistema al crear y dirigir una estructura organizacional jerárquica y delincuencial, a la vez

\footnotetext{
39 Sentencia; p. 625.

${ }^{40}$ Sentencia; p. 633.

${ }^{41}$ Straftaten ...; ob.cit. p. 202.

42 Sentencia; p. 637.
} 
que paralela y encubierta. Primero, por haberse alejado del orden legal establecido y que era la fuente del uso legítimo del poder; y luego, porque al ser conocedor del marco jurídico existente diseña y activa dicha estructura criminal, de modo que resulta menos identificable a las autoridades encargadas de la prevención y control del delito. Por lo tanto, todo aquél que en atención a su jerarquía pone en funcionamiento la maquinaria del aparato de poder organizado, para la comisión del delito, deberá responder siempre como autor mediato» ${ }^{43}$.

Aplicar la teoría roxiniana al caso Ayotzinapa no significa, como equivocadamente pudiese llegar a pensarse por la doctrina mexicana, dejar impunes las acciones ejecutadas por los actores materiales. Por el contrario, como lo deja claro el propio Roxin; «la autoría mediata, por dominio de la voluntad en un aparato organizado de poder, deja incólume la responsabilidad de los autores materiales» ${ }^{44}$. Al mismo tiempo debe considerarse, en armonía con el propio Roxin, que en este tipo de casos «el delito no sería posible sin contar con las personas que se ubican en la punta del aparato» ${ }^{45}$; es decir, que autor mediato y autores materiales cometen un mismo hecho y deben todos responder por el mismo.

\section{El apartamiento del derecho}

El expresidente municipal de Iguala asumió el poder de forma legítima, por lo que mientras se mantuvo en los márgenes permitidos, sus acciones deben ser consideradas igualmente legítimas. Sin embargo, las investigaciones realizadas por la Procuraduría General República arrojarían una desvinculación clara y firme del ordenamiento jurídico, de tal forma que al ordenar la detención de los estudiantes y su posterior entrega al cartel de los guerreros unidos -presumiblemente liderado por su esposa-, se habría apartado radicalmente del ordenamiento jurídico, y aunque actúa con base en la legalidad cuando administra el Municipio, utiliza esa estructura gubernamental para obrar claramente en contra de los tratados internacionales y de la constitución. Véase, al respecto, la argumentación de la Corte Suprema peruana:

«Para Roxin, pues, el apartamiento del Derecho no se refiere únicamente al ordenamiento jurídico interno de cada Estado sino también, y muy particularmente, al Derecho Internacional: Sólo porque todos los pueblos del mundo están vinculados a ciertos valores, tenemos la posibilidad de considerar delictivos y punibles las conductas de órganos superiores del Estado que violen de modo evidente los derechos humanos» ${ }^{46}$.

En su más reciente toma de postura, Roxin matiza el requisito ahora analizado. Si bien es cierto esto en nada cambia lo que se ha sostenido aquí, me parece importante insistir en que, aun considerando necesaria la acreditación de este elemento, salta a la vista su configuración en el caso Ayotzinapa. Esto es así pues, el autor mediato ya identificado, asumió legítimamente el cargo que ostentaba, administraba el Municipio, ejercía recursos públicos y decidía las políticas públicas a implementar en el Municipio a su cargo. Sin embargo, como se confirma por las investigaciones realizadas por la Procuraduría General de la República y de la Fiscalía General del Estado de Guerrero, pesaban sobre él - antes de los hechos acaecidos en Iguala- un par de órdenes de aprehensión, por hechos cometidos en el transcurso de su administración. A estos

\footnotetext{
43 Sentencia; p. 637.

44 Straftaten; ob.cit. p. 200.

45 "Bemerkungen zum Fujimori-Urteil des Obersten Gerichtshofs in Peru; ZIS...; ob.cit. p. 566

${ }^{46}$ Sentencia; p. 641. 
hechos e imputaciones se sumó la acusación por la desaparición de los cuarenta y tres normalistas. Véase, en este sentido, la argumentación de la Corte Peruana acerca de la desvinculación del ordenamiento jurídico en el caso Fujimori:

«La desvinculación del ordenamiento jurídico en la criminalidad estatal puede darse de dos maneras: Primero, cuando el nivel superior estratégico del Estado decide apartarse por completo del derecho y crear un sistema normativo totalmente diferente que no es reconocido ni aceptado por el derecho internacional (...) Esta modalidad resulta ser la más grave porque se cubre con una aparente legitimidad. Sin embargo, subrepticiamente intenta crear un sistema normativo alterno al legalmente vigente, aprovechando, justamente, sus formas y estructuras para la comisión de delitos graves».

\section{La fungibilidad de los actores}

De conformidad con el estado actual de la teoría de la autoría mediata por dominio de la voluntad, puede afirmarse que la fungibilidad del ejecutor se verifica cuando puede ser sustituido por el nivel superior de cara a la ejecución de la orden delictiva. Esto significa que la instrucción girada por el superior jerárquico, en nuestro caso el presidente municipal de Iguala, no corrió riesgo alguno, pues cualquiera de los autores pudo haber sido sustituido por cualquier otro de cara a la consumación de la orden superior. Así, como sostienen Roxin, «el autor mediato puede tener la seguridad en la ejecución del hecho, debido a la fungibilidad de los autores» ${ }^{47}$. De manera muy clara lo expone la Corte Peruana:

«De allí que Roxin, al exponer las características de la fungibilidad, resalte, continuamente, que tal condición garantiza al hombre de atrás la realización del evento criminal y le permite, a su vez, el dominio del hecho. El ejecutor es, pues, simplemente una ruedita cambiable de la máquina del poder, un engranaje sustituible en cualquier momento, pero que ocupará un lugar central en la materialización de los acontecimientos ilícitos» ${ }^{48}$.

A pesar de no compartir la aplicación de la tesis roxiniana para enfrentar el juicio a Fujimiori, García Cavero expone, también, de forma clara el requisito de fungibilidad: «la fungibilidad del ejecutor significa que éste no opera como persona individual, sino como engranaje mecánico. Esta fungibilidad tiene, como se dijo, una expresión negativa y otra positiva. La primera significa que si el ejecutor se niega a actuar, el mando superior puede disponer de otro ejecutor igualmente eficaz, mientras que la segunda está referida a la posibilidad de elegir entre varios ejecutores en la organización ${ }^{49}$. Como sostiene el propio Roxin:

«Tal organización desarrolla una vida que es independiente de la existencia cambiante de sus miembros. Ella funciona de todos modos, de manera automática, sin importar la persona individual del ejecutante» ${ }^{50}$.

\footnotetext{
47 Straftaten; ob.cit. p. 200.

${ }^{48}$ Sentencia...; p. 645; Acerca de la problemática que representa la designación de un "especialista" (no fungible) para ejecutar el hecho delictivo; Ambos, Kai; «Sobre la organización en el dominio de la organización»; InDret $3 / 2011 ;$ p. 5.

${ }^{49}$ La autoría mediata por dominio de la voluntad en aparatos de poder organizados: El caso de Alberto Fujimori Fujimori; ZIS, 11/2009, p. 602.

${ }^{50}$ Dominio de la Organización y Resolución al Hecho; en, La Teoría del Delito en la Discusión Actual; Traducción de Manuel Abanto Vásquez; Grijley, Lima, 2007, p. 513.
} 


\section{La clara predisposición a la realización del hecho ilícito}

El último de los requisitos señalado por Roxin de cara a hacer efectiva su teoría es el relativo a que se verifique una «clara disposición interna del sujeto a la realización del hecho delictivo». Es decir, que los autores deben estar dispuestos - claramente- a la comisión del delito: «la pertenencia a la organización, ya por sí misma, da lugar a una tendencia de adaptación. Se espera que cada uno de los miembros se integre. Esto puede llevar a una cooperación irreflexiva en acciones que jamás se le ocurrirían a una persona que no formara parte de tal organización ${ }^{51}$. Así, por ejemplo, lo expone la Corte Peruana:

«En términos concretos, esta categoría alude a una predisposición psicológica del ejecutor a la realización de la orden que implica la comisión del hecho ilícito. Ya no es la fungibilidad del ejecutor lo que asegura el cumplimiento de aquella, sino el internalizado interés y convencimiento de este último en que ello ocurra» ${ }^{52}$.

Según Ambos - quien se ha ocupado de este tema en múltiples publicaciones-, «la pertenencia voluntaria a la organización puede justificar una elevada disposición al hecho por parte del miembro individual, pero el dominio del hecho se fundamenta sólo en el dominio de la organización -comprendido en términos colectivos-y sólo a través de éste se media sobre los miembros ejecutores del hecho ${ }^{53}$. En el caso de los normalistas de Ayotzinapa hoy desaparecidos, nos encontramos ante un aparato configurado por agentes de la policía de Iguala, que bajo el mando del hoy imputado y en su calidad de presidente municipal, habrían recibido la orden determinando el destino de las víctimas. Éstas habrían sido desaparecidas a manos de policías y miembros del crimen organizado, quienes actuaban -no sólo en este caso, sino de forma sistemática一, como un aparato de poder al mando del presidente municipal y su esposa. Así, por ejemplo, mientras unos operaban acciones delictivas en Iguala (cartel de los «guerreros unidos»), otros habrían servido como «halcones» (policías) para facilitar y encubrir la actividad criminal de los primeros. En los hechos, policía y crimen organizado habrían configurado una misma estructura delictiva y formarían parte de la misma organización: unos amparados por una placa, otros por un arma, pero con mismos objetivos y mismos jefes de la organización.

\section{Perspectivas}

En mi opinión, los elementos que configuran a la autoría mediata, por dominio de la voluntad en un aparato organizado de poder, se cumplirían en el caso del expresidente municipal de Iguala, Guerrero. Así, el hoy procesado, desde el nivel que legítimamente ocupaba como servidor público legalmente electo, habría instrumentado una estrategia de agresión en contra de los 43 normalistas desaparecidos. En su calidad de presidente municipal, y teniendo el mando de la policía municipal, habría girado la orden verbal de "proceder» en contra de los alumnos que se manifestaban de distintas formas, abusando así de su posición de mando y violentando los principios constitucionales que estaba obligado a respetar y hacer respetar.

El expresidente municipal habría utilizado, para tales efectos, el aparato organizado de poder por él presidido y desde la cúspide, en su calidad de "autor de escritorio», habría echado a an-

\footnotetext{
${ }^{51}$ Roxin, Claus; Dominio... ob.cit. p. 531.

52 Sentencia; p. 649.

53 "Sobre la organización...; ob.cit. p. 8.
} 
dar de forma ilegítima la maquinaria punitiva, configurada por fuerzas del Estado y miembros del crimen organizado - que en su conjunto actuaban de forma automática-, apartándose de esta forma del ordenamiento jurídico nacional e internacional. Para alcanzar su objetivo, el hoy procesado habría omitido la orden verbal de proceder y, tal y como se deriva de las investigaciones realizadas por la Procuraduría General de la República, dando seguimiento a su ejecución durante la noche del 26 y madrugada del 27 de septiembre, hasta que los hechos se habían consumado.

La estrategia presuntamente implementada por el líder de la organización, habría incluido la colaboración de miembros del crimen organizado identificados como «cartel de los guerreros unidos», a quienes policías bajo el mando directo del entonces presidente municipal, habrían entregaron a los cuarenta y tres normalistas desaparecidos. El control que el «autor de escritorio» ejercía sobre la policía y su coordinación con el cartel de «guerrero unidos», le habría asegurado en todo momento la ejecución de los hechos, independientemente de conocer o no a quienes materialmente cumplirían sus designios, pues tales autores tendrían la condición de fungibles, de tal forma que si uno de los policías o miembros del crimen organizado no ejecutase la orden, sería inmediatamente sustituido por otro, quien la llevaría al cabo, debido a su clara disposición al hecho delictivo.

La desaparición de los cuarenta y tres normalistas de Ayotzinapa, la muerte de otros tres, los veinticinco lesionados, así como la victimización de civiles que se encontraban en el lugar de los hechos, constituyen una grave violación a los derechos humanos, que en mi parecer, configuran los delitos de desaparición forzada de personas en concurso con homicidio múltiple, lesiones y delincuencia organizada, cometidas bajo los principios de la autoría mediata, por dominio de la voluntad, en un aparato organizado de poder. 